\title{
Editorial
}

\section{Investigación y ciencia: implicaciones para un docente investigador en el sistema colombiano}

\author{
Ana María Mosquera-Ayala \\ Comunicadora social, líder de producción bibliográfica \\ Universidad La Gran Colombia
}

$\mathrm{V}$

oluminosos descubrimientos científicos se realizan con frecuencia en diferentes partes del mundo. Generalmente, la socialización de estos se desarrolla a partir de la academia y sus procesos de divulgación a la investigación, cuyos productos: artículos, libros, capítulos de libros, patentes, entre otros, representan un gran indicador de desarrollo para la ciencia, la tecnología y la innovación en cada país.

Colciencias es el organismo en Colombia encargado de registrar y reconocer la investigación. A partir del año 2001 se empezó a vivir un proceso de transición en la difusión y divulgación del conocimiento científico, al diseñar todo un sistema de ciencia y tecnología que clasifica investigadores, grupos, y revistas, en categorías cuyas bondades, le confieren prestigio y reconocimiento al investigador. La constante actualización de los modelos de evaluación del sistema hace posible la medición de la calidad, estabilidad y el impacto de la investigación (Publindex, 2016). Dicho esto, el objetivo de este texto es señalar las implicaciones que tiene un investigador para alcanzar y mantenerse en los estándares del sistema colombiano.

Si usted es un docente al que le han asignado horas de investigación, se le sugiere tener en cuenta los siguientes procedimientos: lo primero con lo que se debe familiarizar es con Colciencias y sus modelos de medición, los cuales establecen todos los requisitos para ser reconocido como investigador, también para pertenecer a un grupo, o le brinda pautas de publicación a la luz de sus propios criterios.

Como se dijo, desde hace 18 años Colciencias se encarga de medir y visibilizar la investigación en el país. Siendo así, lo segundo con lo que usted se va a familiarizar es con el CVlac, este es un aplicativo en el cual se construye el perfil de un investigador a través del registro de toda la actividad
Mosquera-Ayala, A.M. (2018) Investigación y ciencia: implicaciones para un docente investigador en el sistema colombiano. Sophia, $14(2), 1-3$. 
académica e investigativa: sus nombres y apellidos, estudios realizados, horas de clase impartidas, trabajos de grado dirigidos, libros y artículos publicados, entre otros ítems. Lo siguiente, será identificar el material de lectura que requiere para trazar el objetivo a conseguir, necesita conocer las reglas de juego para entrar en él; comprender el modelo de medición le permitirá proponerse metas posibles de cumplir y establecer el tiempo adecuado para mejorar su categoría como investigador o la de su grupo.

Una vez que usted tenga claro los modelos de medición y el objetivo a cumplir, proponga su tema de investigación, organice su grupo de trabajo y plantee con su equipo los productos a entregar de acuerdo con la naturaleza de su investigación, para ello, es necesario tener claro específicamente el puntaje que suma cada producto de su investigación según el modelo de medición. Consulte el modelo en el siguiente enlace: https://goo.gl/AqyN1m

El sistema propone una escala de ascenso entre cada categoría, para ascender se deben cumplir los requisitos del modelo, los cuales están íntimamente ligados con la suma de los puntajes de cada producto y el grado académico de cada integrante que se haya registrado en el CVLac y que hayan sido arrastrados por el GRupLac. Así como el investigador tiene un perfil de CVLac, los grupos de investigación tienen también su propio perfil GRupLac el cual funciona de la misma forma, va registrando la entrega de los productos de cada integrante del grupo y esto determinará a la hora de la evaluación el ascenso o no a la siguiente categoría.

A pesar de que la elaboración del producto a entregar es la parte final de la investigación, esta es la parte inicial del proceso de divulgación. Es decir, una vez que se tiene listo el producto, (artículo, libro, capítulo de libro, informe, u otro) lo siguiente es realizar una buena elección del medio en que se va a divulgar. La elección de una buena revista es un proceso fundamental, ya que de esto depende la visibilidad y el alcance de su trabajo, y finalmente, el impacto. Aprenda a identificar el medio para la socialización de sus resultados. Tenga en cuenta lo siguiente: una buena revista científica se evalúa a través de la indexación de sus contenidos en diferentes bases de datos, índices o repositorios institucionales. Estos son los lugares donde se encuentran la literatura científica, tanto artículos como tesis de pregrado y postgrado, entre otros documentos. Adicionalmente, se reconoce una buena revista a través de la consulta de su factor de impacto, esta se puede realizar en Google Scholar, en la opción "estadísticas" o en la plataforma "Publish or Perish" tecleando el nombre de la revista o su ISSN, inmediatamente le mostrará la medida de impacto, que es la suma de sus artículos publicados dividida por la cantidad de citas recibidas, generalmente, se realiza esta medida en ventanas de observación de 3 años.

Otras opciones para elegir una buena revista son: fijar la atención en la cantidad de ediciones publicadas, el cumplimiento de la periodicidad declarada, y el nombre de la entidad editora. Además de esto, otra alternativa es revisar la base de datos de Colciencias, o de los entes reguladores de la investigación en cada país.

Además de elegir un buen medio, un docente con horas para investigar debe saber que la mitad de sus compromisos como investigador requieren de buenas habilidades escriturales. Esto implica plantearse la siguiente pregunta: ¿Cómo y para qué se hace ciencia hoy?

La ciencia hoy en día se divulga a través de los llamados artículos científicos en revistas especializadas y categorizadas. Estos son escritos donde se socializan los hallazgos de una investigación, aproximadamente contienen entre 20 a 25 páginas, suelen venir acompañados con gráficos, abundantes citas entre paréntesis, y son revisados minuciosamente por pares.

La escritura de artículos es una práctica decisiva en el ámbito académico, el reconocimiento de un investigador se consolida mediante el número de citas que se hagan de sus productos, lo que se conoce como el Índice $\mathrm{h}^{1}$, este criterio cambió la forma de evaluar la calidad científica de las publicaciones; anteriormente, lo que se medía era el número o cantidad de artículos publicados, hoy en día, se evalúa la citación, esto implica que un artículo que alcance un índice alto es porque ha servido de insumo a la comunidad científica, por lo tanto, es un documento que aporta conocimiento a la disciplina y confirma la validación del saber científico. Así lo afirman Mireya Cisneros y Giohanny Olave:

Hoy en día, por ejemplo, aunque las ponencias en eventos se exponen oralmente y con ayuda de imágenes, queda como constancia en las memorias un texto escrito y solo así los conocimientos comunicados pueden ser posteriormente citados en la seriedad de un nuevo texto portador de ciencia (Cisneros y Olave, 2008:122).

1 El Índice h es el balance entre el número de publicaciones y las citas a estas, la fórmula que permite hacer esta medición fue postulada por Jorge Hirsch. 
Elaborar un artículo científico le puede costar a un investigador uno o dos años de trabajo; uno y medio, en el trabajo de campo: recolección de información, análisis, discusión de resultados y conclusiones, y finalmente, alrededor de seis meses elaborando el producto a publicar. Esto quiere decir que si va a invertir tanto tiempo y esfuerzo en un proceso, este merece cumplirse a través de un medio adecuado. Tenga en cuenta que el tiempo de un buen proceso editorial se estima entre seis meses y un año; un año en el que nuevamente será revisado, fuertemente criticado por otros colegas, para finalmente llegar a la mejor versión del texto.

Usted puede evitar estancarse varios meses en un proceso editorial, si previamente lee las normas de la revista en la que ha decidido postular su manuscrito, concluya su texto a la luz de las normas; no improvise, no se invente una nueva estructura, envíe el material gráfico con una resolución adecuada, utilice la estructura IMRYD si el texto es resultado de investigación (Introducción, materiales y métodos, resultados y discusión) o una estructura menos rígida si es de reflexión, y exprese claramente el componente innovador de su investigación, esto le evitará posibles fracasos.

Más allá de todo lo expuesto, existen otros factores que contribuyen a crear el perfil de un docente investigador. Además de conocer los procesos investigativos, sus respectivos productos, puntajes y formas de divulgación, el docente deberá adoptar las nuevas tecnologías de la información disponibles hoy en día, las cuales fueron desarrolladas con el fin de facilitar sistemáticamente la medición de indicadores de impacto.

Algunos de estos desarrollos tecnológicos son: el primero, la creación de un perfil en $O R C I D$. Este es un sistema que proporciona un identificador digital que lo distingue de cualquier otro investigador $\mathrm{y}$, a través de la presentación de manuscritos y productos de investigación, respalda los vínculos automatizados entre usted y sus actividades profesionales asegurando que su trabajo sea reconocido. El segundo, registrar sus datos como investigador en Research ID, este es un sistema que recupera y almacena sus datos como investigador para que usted sea reconocido siempre de la misma forma en internet. Por ejemplo: si su nombre es Juan Perez Arrieta, y de repente usted reconoce otro Juan Pérez en internet, entonces usted deberá realizar la estandarización de su firma personalizándola con el segundo apellido en el Research ID así: (Pérez-Arrieta, J.) con el fin de que no se extravíen las citas que reciba toda su producción académica. De la misma forma, se debe realizar la estandarización de las instituciones editoras, ya que son colocadas de distintas formas por los investigadores y esto ocasiona algunos inconvenientes a la hora de conceder las citas. El tercero, usted deberá crear su perfil académico en Google Scholar para que este sistema lo reconozca también como investigador a través del movimiento de citas hacia sus trabajos; crear un perfil en Scholar contribuye a conocer su factor de impacto fácilmente digitando el nombre del investigador en "estadísticas" de esta manera se nos desplegará todo nuestro universo académico ordenado de mayor a menor tiempo de publicación y acumulando las citas de cada trabajo.

Por último, uno de los aspectos más importantes que debe cultivar un investigador es la paciencia para recoger los frutos de su cosecha. Algunos procesos investigativos no son tan ágiles, de allí que algunos investigadores manifiestan inconformidades en los tiempos de edición, teniendo en cuenta, como infiere De ambrosío (2018), que están atrapados en una maquinaria que necesita de sus publicaciones como el oxígeno para su propia supervivencia, pero en algunos casos, es independientemente de su calidad y, en especial, de su relevancia. Muchos investigadores infieren que el 50\% de los trabajos solo serán leídos por los coautores, los revisores y los editores del journal, dejando claro que existe una falla en el sistema con relación a los artículos científicos que tiene que ver con el esfuerzo y el tiempo dedicado versus la recompensa.

\section{Referencias bibliográficas}

De Ambrosio, M. (2018) El drama de escribir papers para casi nadie. Clarin, revista N. https://www. clarin.com/revista-enie/ideas/drama-escribir-papers-nadie_0_Hk77ydRQX.html

Estupiñán, M. C y Olave, G. O. (2012). Redacción y publicación de artículos científicos: enfoque discursivo. Bogota: Ecoe Ediciones.

Publindex (2016). Documento guía para el servicio permanente de indexación de revistas seriadas de ciencia tecnología e innovación colombianas del Departamento Administrativo de Ciencia, Tecnología e Innovación. Colciencias. Bogotá. Recuperado de: http://publindex.colciencias. gov.co:8084/publindex/EnIbnPublindex/ resultados.do 